\title{
THE EFFECT OF ION IRRADIATION ON INERT GAS BUBBLE MOBILITY*
}

\author{
D. E. Alexander and R. C. Birtcher \\ Materials Science Division \\ Argonne National Laboratory \\ Argonne, IL 60439
}

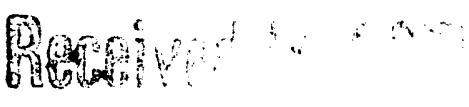

OCT 281991

September 1991

\section{DISCLAIMER}

\begin{abstract}
This report was prepared as an account of work sponsored by an agency of the United States Government. Neither the United States Government nor any agency thereof, nor any of their employees, makes any warranty, express or implied, or assumes any legal liability or responsibility for the accuracy, completeness, or usefulness of any information, apparatus, product, or process disclosed, or represents that its use would not infringe privately owned rights. Reference herein to any specific commercial product, process, or service by trade name, trademark, manufacturer, or otherwise does not necessarily constitute or imply its endorsement, recommanufacturer, or otherwise does not necessarily constitute or imply its endorsement, recomand opinions of authors expressed herein do not necessarily state or reflect those of the United States Government or any agency thereof.
\end{abstract}

Submitted to the Fifth International Conference on Fusion Reactor Materials, Clearwater, FL, November 17-21, 1991.

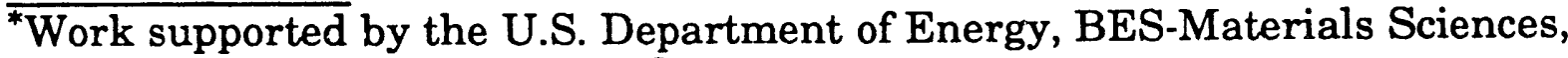
under contract \#W-31-109-ENG-38.
} 
The Effect of Ion Irradiation on Inert Gas Bubble Mobility

Dale E. Alexander and R.C. Birtcher

Materials Science Division

Argonne National Laboratory

9700 S. Cass Ave.

Argonne, II 60439

\begin{abstract}
The effect of $\mathrm{Al}$ ion irradiation on the mobility of $\mathrm{Xe}$ gas bubbles in $\mathrm{Al}$ thin films was investigated. Transmission electron microscopy was used to determine bubble diffusivities in films irradiated and/or annealed at $673 \mathrm{~K}, 723 \mathrm{~K}$ and $773 \mathrm{~K}$. Irradiation increased bubble diffusivity by a factor of 2-9 over that due to thermal annealing alone. The Arrehnius behavior and dose rate dependence of bubble diffusivity are consistent with a radiation enhanced diffusion phenomenon affecting a volume diffusion mechanism of bubble transport.
\end{abstract}




\section{Introduction}

An understanding of the behavior of helium gas bubbles in fusion reactor materials is important because it affects structural, mechanical and thermal material properties which in turn determine performance characteristics and service lifetimes of reactor components. Swelling, blistering, grain boundary weakening, etc. depend in large part on the mobility of bubbles in materials. While the subject of considerable study during the past 30 years, very little is known about the microscopic effects of irradiation on the motion of inert gas bubb'es. The intense neutron fluxes expected to be produced in fusion reactors combined with the importance of bubble behavior on material properties makes an understanding of irradiation effects on bubble mobility essential.

Ion irradiation and implantation offer unique tools to accomplish such irradiation effects studies. Irradiation with self-ions permits the simulation, on a shorter time scale, of damage induced by neutrons, their primary recoils and energetic nuclear reaction products expected in firstwall and blanket materials of a fusion reactor.

The work described in this paper was undertaken to investigate the effect of self-ion irradiation on the microscopic behavior of Xe bubble migration in Al thin films. Previously, Luklinska and Goodhew [1], observed no effect of $\mathrm{Cr}$ ion irradiation on the mobility and growth of He bubbles in a $12 \% \mathrm{Cr}$ ferritic steel. Analysis of bubble growth due to annealing-alone in that study indicated that bubble migration took place via a slow, ledge mechanism process. In pure $\mathrm{Al}$ however, a different bubble migration mechanism has been observed. Yamaguchi et al. [2] performed experiments suggesting that migration of $\mathrm{Kr}$ bubbles in $\mathrm{Al}$ occurs via volume diffusion. It is conceivable that irradiation could alter mobility in bubbles migrating via a volume diffusion mechanism through radiation enhanced diffusion [3]. It is therefore of interest to evaluate the affect of self-ion irradiation on bubble mobility in $\mathrm{Al}$.

\section{Experimental}

Thin ( $75 \mathrm{~nm})$ aluminum films were electron-beam evaporated onto cleaved pieces of (100) single crystal $\mathrm{NaCl}$, held at $623 \mathrm{~K}$, in a vacuum system with base pressure of $1.2 \times 10^{-8}$ torr. Films were highly textured with grains oriented predominantly about the $\langle 111>$ direction. Subsequent to deposition, the films were floated off onto 300 mesh Mo transmission electron microscopy (TEM) grids by dissolving pieces of the $\mathrm{NaCl}$ in distilled $\mathrm{H}_{2} \mathrm{O}$.

Films were implanted with $100 \mathrm{keV} \mathrm{Xe,} 5^{\circ}$ off sample normal, at $673 \mathrm{~K}$ in order to precipitate inert gas bubbles for subsequent mobility studies. This energy was chosen to center the implanted Xe concentration profiles at about one-half the Al film thickness. Two of the samples (\#20 and \#31) were implanted to a dose of $5 \times 10^{18} \mathrm{~m}^{-2}$ while the remaining one (\#35) was implanted to $1 \times 10^{19} \mathrm{~m}^{-2}$. Subsequent to implantation, $X$-ray energy dispersive spectroscofy in 
TEM detected small amounts of $\mathrm{Cu}(0.2$ at.\%) in the films likely resulting from $\mathrm{Cu}$ disks used as backing support for the TEM grid during implantation.

Samples were irradiated and annealed in a double-tilt heating stage in the High Voltage Electron Microscope (HVEM)/Tandem facility at Argonne National Laboratory [4]. Each sample was treated at one of three temperatures- $673 \mathrm{~K}, 723 \mathrm{~K}$ or $773 \mathrm{~K}$ - all of which are greater than $2 / 3 \mathrm{~T}_{\mathrm{m}}$ for $\mathrm{Al}\left(\mathrm{T}_{\mathrm{m}}=933 \mathrm{~K}\right.$ ) (see Table $)$. Irradiations were performed using 35 or $70 \mathrm{keV} \mathrm{Al}$ ions at a dose rate of $1.7 \times 10^{16} \mathrm{~m}^{-2} \mathrm{~s}^{-1}$ to a total dose of $10^{20} \mathrm{~m}^{-2}$. TRIM [5] calculations yield fairly uniform damage profiles within the films and averaged about $6 \mathrm{dpa}(70 \mathrm{keV})$ and $8 \mathrm{dpa}(35 \mathrm{keV})$ for a dose of $10^{20} \mathrm{~m}^{-2}$. The samples at $673 \mathrm{~K}$ and $773 \mathrm{~K}$ were first irradiated at their respective temperatures and then annealed without irradiation for a time comparable to that required for irradiation $(\leq 120$ $\mathrm{min})$. The reverse order was applied to the sample treated at $723 \mathrm{~K}$. Subsequent to these initial irradiation and annealing treatments, sample \#35 was irradiated to an additional dose increment of $10^{20} \mathrm{~m}^{-2}$ at $673 \mathrm{~K}$ using a higher dose rate $-5 \times 10^{16} \mathrm{~m}^{-2} \mathrm{~s}^{-1}$.

Bubble mobility was characterized by determining the diffusivity associated with a given bubble population for each sample and treatment. Assuming Brownian motion of bubbles in three dimensions, the measurement of the mean square bubble displacement, $\left\langle x^{2}\right\rangle$, in two dimensions is related to a three dimensional bubble diffusivity, $D$, according to $4 \mathrm{Dt}=\left\langle\mathrm{x}^{2}\right\rangle$, where $t$ is the lime of diffusion. In order to measure values of bubble displacement, $x$, the procedure below was followed.

Microstructures of the Xe implanted Al films were examined before and after irradiation and annealing treatments using a Phillips CM-30 operated at 200kV. Sample grid orientation and areas of the samples were carefully identified for subsequent relocation in the CM-30 following treatment in the HVEM. A reference grain was identified in each area viewed, and was oriented in a $<111>$ direction via tilting and observation of the grain's convergent beam electron diffraction (CBED) pattern. Images of the microstructure were recorded at $120 \mathrm{kX}$. Prints of the negatives were recorded at about $2.5 \mathrm{x}$ magnification and then were digitized using a Microtek scanner at a a resolution of 200 dots per inch. At the print magnification used, this resulted in a resolution of about $0.4 \mathrm{~nm} /$ pixel on the digitized image. For each sample, bubbles were identified in a single grain that were present in images of each of the treatments performed (as-implanted, irradiated and annealed). The analysis program Image [6] was used to locate bubble coordinates and to measure bubble diameters, both in units of pixels. Uncertainty in bubble location is estimated at \pm 1 pixel $( \pm \sim 0.4 \mathrm{~nm})$ in each of the planar coordinates. Diam. iers for the larger bubbles (which were hexagonal in shape) were measured as the perpendicular distance between two opposite sides of the hexagon. Since image focus conditions varied slightly between treatments for a sarnple, measured bubble diameters also varied slightly. Therefore an average diameter $(2 R)$ was obtained 
for each bubble using the diameters measured for the bubble in each of the three treatments (asevaporated, annealed and irradiated).

In the absence of fixed landmarks in the film microstructure, it was necessary to reference bubble migration relative to the center-of-mass (COM) of the bubble population. Presuming Brownian bubble motion, the COM should remain fixed during migration, and therefore fixed between treatments. Two independent transformations of the raw bubble coordinate data were required prior to mobility analysis. A rotation transformation of coordinates, about the COM, of one images bubbles relative to another was necessary in order to accommodate siight angular misorientations between the images. These misorientations, typically $\leq 4^{\circ}$, occurred due to slight differences in sample grid placement in the CM-30 between HVEM treatments and slight variations in print placement on the image scanner bed. The other transformation involved the magnification scaling of one image's bubble coordinates with respect to another as necessitated by small uncertainties, typically $\leq 1 \%$, in the exact TEM magnification. The transformations were accomplished by minimizing the value of $\left\langle x^{2}\right\rangle$ where $x$ is the displacement of a bubble before and after a given treatment as measured by the difference is bubble coordinates referenced to the COM.

\section{Results}

The transformed coordinate data were used to construct plots of the migration distance and migration direction of bubbles from their original positions. Fig. 1 shows this plot for the sample treated at $673 \mathrm{~K}$.

The magnitude of the displacements, $x$, (see Fig. 1) combined with treatment times were used in $\left\langle x^{2}\right\rangle=4 D$ t to determine bubble diffusivities. Table I shows the bubble diffusivity values determined for all bubbles at the three temperatures for irradiation and annealing treatments while Table II gives the average diffusivities as a function of bubble diameter (2R).

The results from Table II are used to construct the plot shown in Fig. 2 comparing the diffusivity for the different treatmerts as a function of bubble size and sample temperature. Data from only those size bins consisting of at least 16 bubbles are included in the plots.

The Arrehnius behavior of bubble migration is shown in Fig. 3 where data from size bins consisting of at least 24 bubbles are shown. The activation energy, $Q$, for thermal bubble diffusion calculated from the slopes of these lines was determined to be $1.2 \mathrm{eV}$ and $1.5 \mathrm{eV}$ for the 4-5nm and 5-6nm bubble sizes, respectively. Likewise, for irradiation treatments, the activation energies were determined to be $0.6 \mathrm{eV}$ and $0.7 \mathrm{eV}$ for the $4-5 \mathrm{~nm}$ and $5-6 \mathrm{~nm}$ sizes, respectively. 


\section{Discussion}

The enhancement in bubble migration during ion irradiation is clearly evident in the experimental results of this study. This enhancement is exemplified by the significantly larger displacement distances observed during irradiation in Fig. 1(a) versus the annealing affects shown in Fig 1(b). At each temperature, the bubble diffusivity during irradiation, determined for all the bubbles regardless of size, is a factor of $\sim 2-9$ times greater than that observed during annealing at the same temperature without irradiation (see Table $\mathrm{I}$ ).

Bubble mobility is also known to be a strong function of bubble size [7]. The results of the annealing experiments shown in Fig. 2 (closed symbols) are consistent with the inverse size dependence observed previously for thermal gas bubble mobility [7]. However, the results of mobility size dependence for the irradiation treatments (open symbols in Fig. 2) differ from those observed thermally. While consistent with the temperature dependence observed during the annealing treatment, the anticipated size dependence is absent in the two low temperature irradiations. Fig. 2 shows that at $673 \mathrm{~K}$ and $723 \mathrm{~K}$ the diffusivity is fairly independent of bubble size. Only at $773 \mathrm{~K}$ is a decrease in bubble diffusivity observed with increasing bubble size. It is also noted that for the largest bubble size $(6-7 \mathrm{~nm})$ mobilities during irradiation at each of the temperatures are nearly the same.

The analysis of the Arrehnius behavior of bubble mobility (Fig. 3) resulted in values of activation energy for thermal migration close to that determined for self-diffusion of $\mathrm{Al}, 1.5 \mathrm{eV}$ [8]. This suggests that volume diffusion may be the operative kinetic mechanism in thermal bubble transport in support of the previous work by Yamaguchi et al. [2]. In such a case, the enhancement in bubble mobility observed during irradiation may be attributed to a radiation enhanced diffusion process. When point defects produced by ion irradiation annihilate by recombination, the radiation enhanced volume diffusivity, $D_{\text {vol }}^{\prime}$, of matrix atoms may be described by [3],

$$
D_{\mathrm{vol}}^{\prime}=A \exp \left(\frac{\mathrm{Q}}{2 \mathrm{kT}}\right) \sqrt{\dot{\Phi}}
$$

where $\dot{\Phi}$ is the dose rate. Since bubble diffusivity is directly proportional to volume diffusivity [7], eqn.(1) implies that the activation energy for migration during irradiation should be $1 / 2$ that observed thermally. This was indeed observed for the limited amount of data as presented in Fig. 3. Furthermore, eqn.(1) indicates that bubble mobility during irradiation should be dose rate dependent. As shown in Table $\mathrm{I}$, for the $673 \mathrm{~K}$ irradiation, a factor of 3 increase in dose rate resulted in a factor of 1.82 increase in bubble diffusivity consistent with the expected increase of $\sqrt{3}(\approx 1.73)$. Both of these results, measured activation energies and dose rate dependence, 
support the idea that bubble mobility in Al during ion irradiation is enhanced via a radiation enhanced ciffusion process.

The diffusivity values for high temperatures observed in this work are 3-4 orders of magnitude smaller than those previously attributed to $\mathrm{Kr}$ bubble diffusion in Al. Takaishi et al. [9] performed gas release extraction experiments in which bubble diffusivities were calculated to be between $2.7 \times 10^{-19} \mathrm{~m}^{2} / \mathrm{s}$ and $3.9 \times 10^{-18} \mathrm{~m}^{2} / \mathrm{s}$ in the temperature range of $713 \mathrm{~K}-813 \mathrm{~K}$. Differences between this work and the previous study are expected due to different implanted species (Xe vs. $\mathrm{Kr}$ ) implant temperature (673K vs. $300 \mathrm{~K})$, and the fact that some $\mathrm{Cu}$ impurity is present in the films used for this work. However, these differences are not expected to account for the large discrepancies observed. Clearly, direct bubble migration measurements, of the type performed in this and previous work [2], are the optimal for evaluating bubble mobility. Extraction experiments determine bubble diffusivity indirectly assuming an analytical model for release, and an initial implanted gas profile, both of which are susceptible to error. Takaishi et al. [9] assume that all the implanted gas is in bubbles, which, in the absence of experimental evidence, is questionable for the room temperature implant performed. The work also failed to consider that gas release may occur when bubbles approach within a distance $R$, equal to the bubble radius, to the film surface effectively reducing the modelled release distance. It is therefore conceivable that the actual bubble mobility is considerably less than the values quoted in the extraction data study. Additional experiments are clearly warranted to further evaluate this discrepancy.

\section{Acknowledgements}

The authors gratefully acknowledge the assistance of Loren Funk in performing implantations and ion irradiations at the HVEM/Tandem Facility and to L. Rehn for insightful discussion. This work performed under DOE Contract No. W-31-109-ENG-38.

\section{References}

[1] Z.H. Luklinska and P.J. Goodhew, J. Nucl. Mater. 135 (1985) 201.

[2] H. Yamaguchi, I. Hashimoto, H. Mitsuya, K. Nakamura and E. Yagi, J. Nucl. Mater. 161 (1989) 164.

[3] R. Sizmann, J. Nucl. Mater., 69/70 (1978) 386.

[4] C.W. Allen, L.L. Funk, E.A. Funk, E.A. Ryan, and A. Taylor, Nucl. Instrum. Methods B 40/41 (1989) 553.

[5] J.P. Biersack and L.G. Haggmark, Nucl. Iıstrum. Methods 174 (1980) 257. 
[6] Electron Microscopy Society of America Bulletin 21 \#1 (1991) 83.

[7] P.J. Goodhew and S.K. Tyler, Proceedings of the Royal Society of London A377 (1981) 151.

[8] Smithells Metals Reference Book, 6th edition, Ed. E.A. Brandes (Butterworths, London, 1983) p.13-5.

[9] K. Takaishi, T. Kikuchi, K. Furuya, I. Hashimoto, H. Yamaguchi, E. Yagi and M. Iwaki, Phys. Stat. Sol. (a) 95 (1986) 135. 
Table I. Bubble mobility data for samples and treatments studied. Diffusivity values are averages for all bubbles independent of bubble size.

\begin{tabular}{|cccccccc|}
\hline \hline Sample & $\begin{array}{c}\text { Temperature } \\
(\mathrm{K})\end{array}$ & $\begin{array}{c}\text { Number } \\
\text { of } \\
\text { Bubbles }\end{array}$ & $\begin{array}{c}\text { Average } \\
2 \mathrm{R} \\
(\mathrm{nm})\end{array}$ & $\begin{array}{c}\mathrm{Al}^{+} \\
\text {Energy } \\
(\mathrm{keV})\end{array}$ & $\begin{array}{c}\text { Dose } \\
\text { Rate } \\
\left(\times 10^{16} / \mathrm{m}^{2} / \mathrm{s}\right)\end{array}$ & $\begin{array}{c}\mathrm{D}_{\text {irr }} \\
\left(\times 10^{-22} \mathrm{~m}^{2} / \mathrm{s}\right)\end{array}$ & $\begin{array}{c}\mathrm{D}_{\text {th }} \\
\left(\times 10^{-22} \mathrm{~m}^{2} / \mathrm{s}\right)\end{array}$ \\
\hline$\# 20$ & 673 & 227 & 4.9 & 35 & 1.7 & 1.81 & 0.22 \\
$\# 20$ & 673 & 198 & 5.0 & 35 & 5.0 & 3.29 & - \\
$\# 31$ & 723 & 71 & 4.1 & 70 & 1.7 & 3.50 & 1.81 \\
$\# 35$ & 773 & 53 & 5.8 & 70 & 1.7 & 6.56 & 2.07 \\
\hline \hline
\end{tabular}




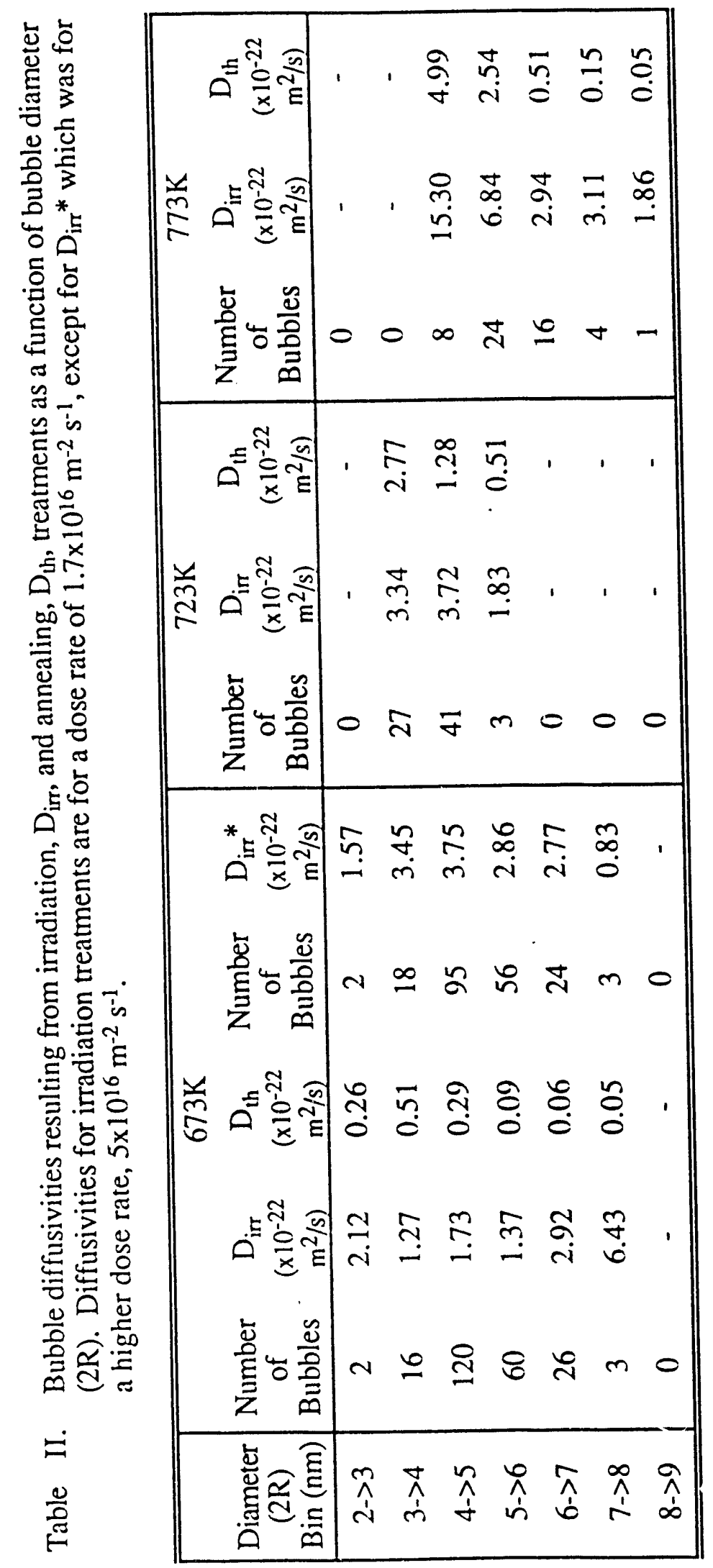




\section{Figure Captions}

Fig. 1. Displacement of bubbles from their original positions (represented by the origin) following irradiation and annealing treatments at $673 \mathrm{~K}$. (a) irradiated with $35 \mathrm{keV} \mathrm{Al}$ to a dose of $10^{20} / \mathrm{m}^{2}$ in $6.96 \times 10^{3} \mathrm{~s}$. (b) annealed without irradiation for $7.20 \times 10^{3} \mathrm{~s}$.

Fig. 2. Bubble diffusivity as a function of bubble diameter (2R) for irradiation (irr) and thermal annealing (th) treatments at varying temperatures. (*) indicates sample ir:adiated at high dose rate $\left(5 \times 10^{16} / \mathrm{m}^{2} / \mathrm{s}\right)$.

Fig. 3. Arrehnius behavior of bubble mobility for selected bubble sizes during irradiation (irr) and thermal annealing (th). Activation energy, $Q$, for bubble migration determined from slopes of resulting lines. 
FIG. 1

(a)

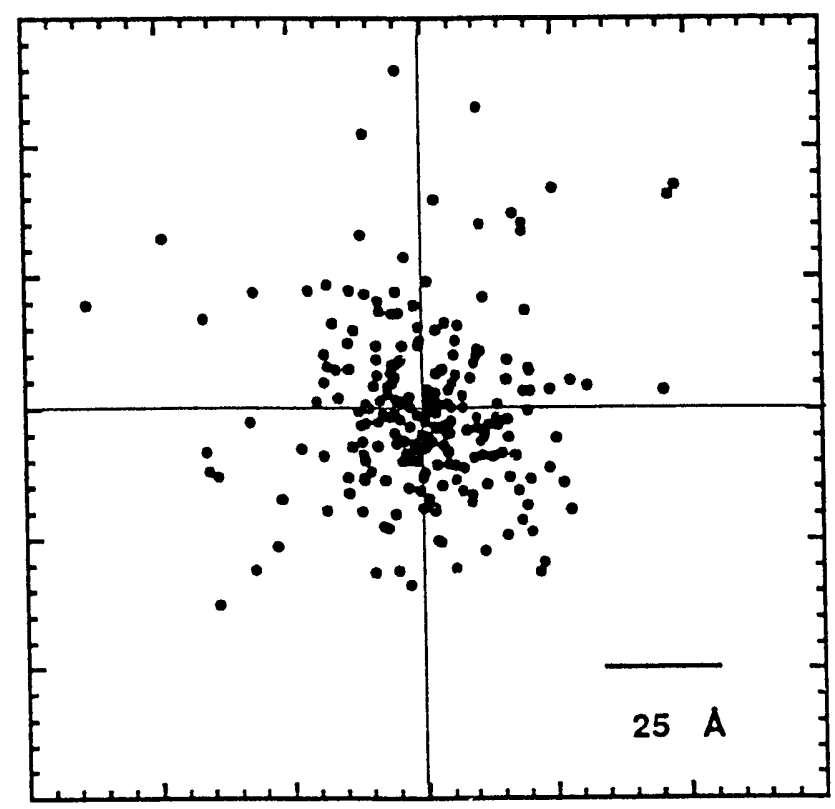

(b)

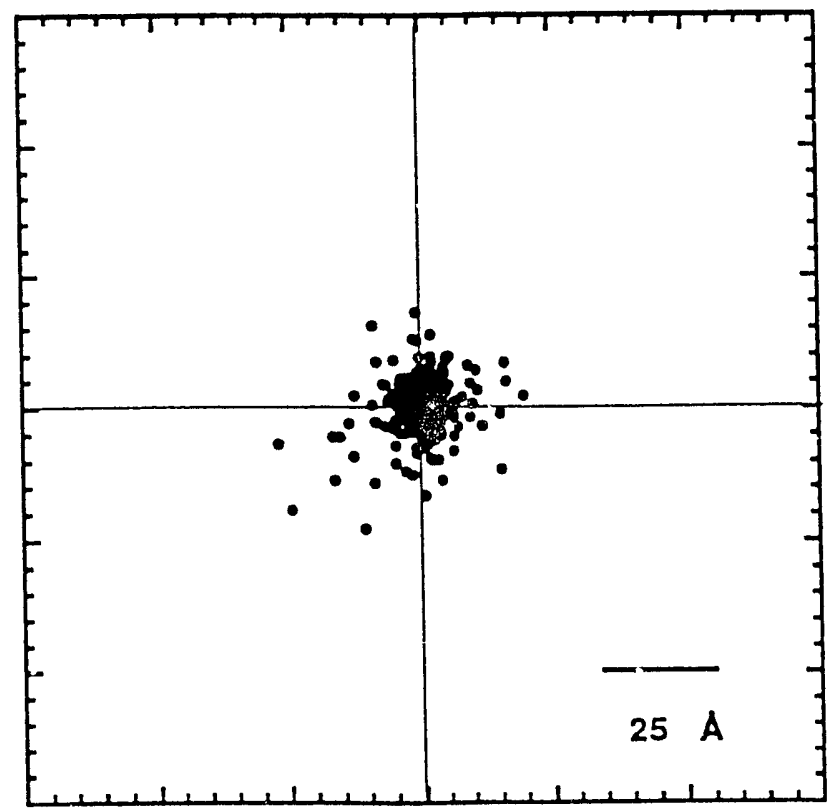


FIG. 2

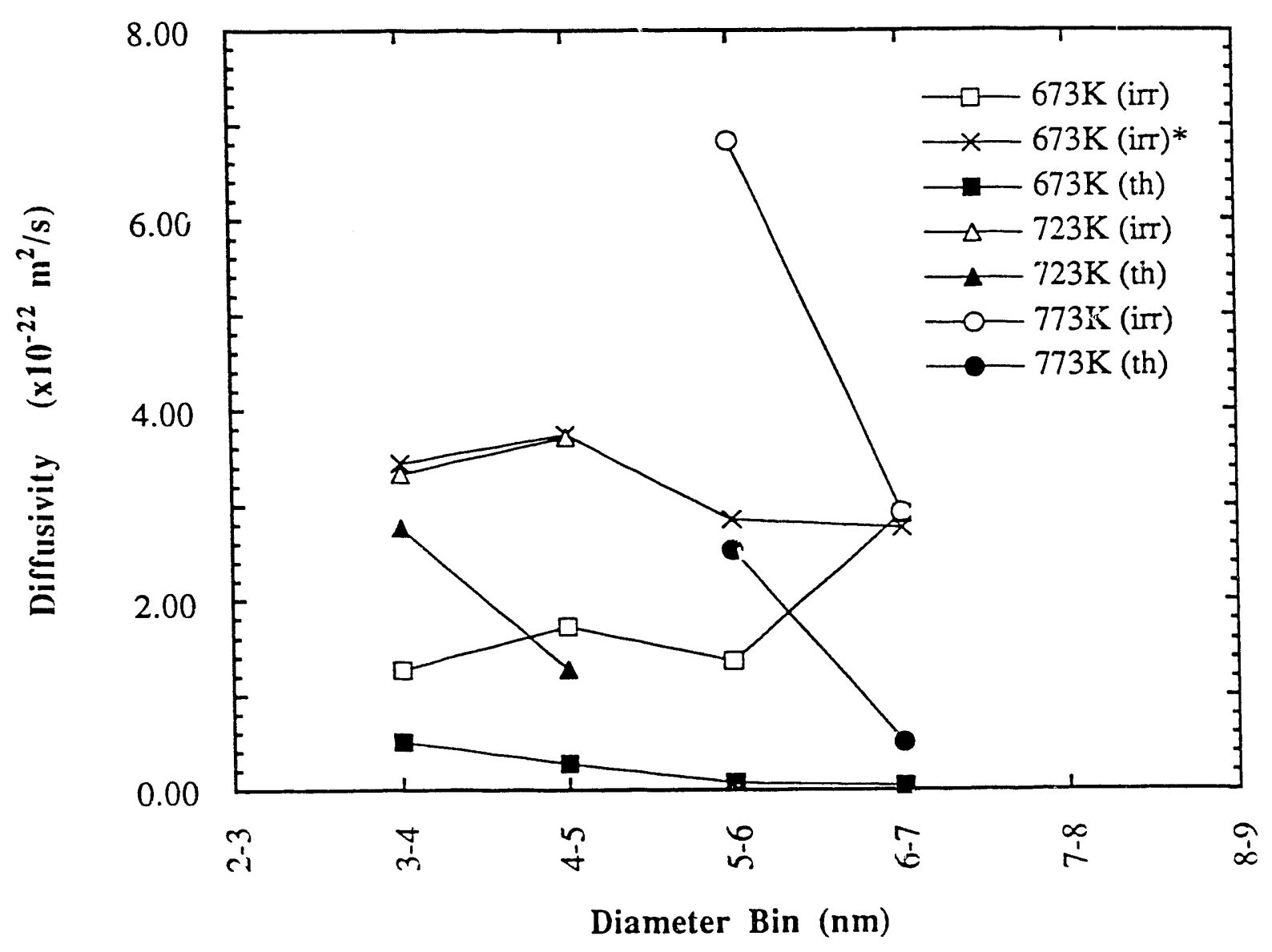


FIG. 3

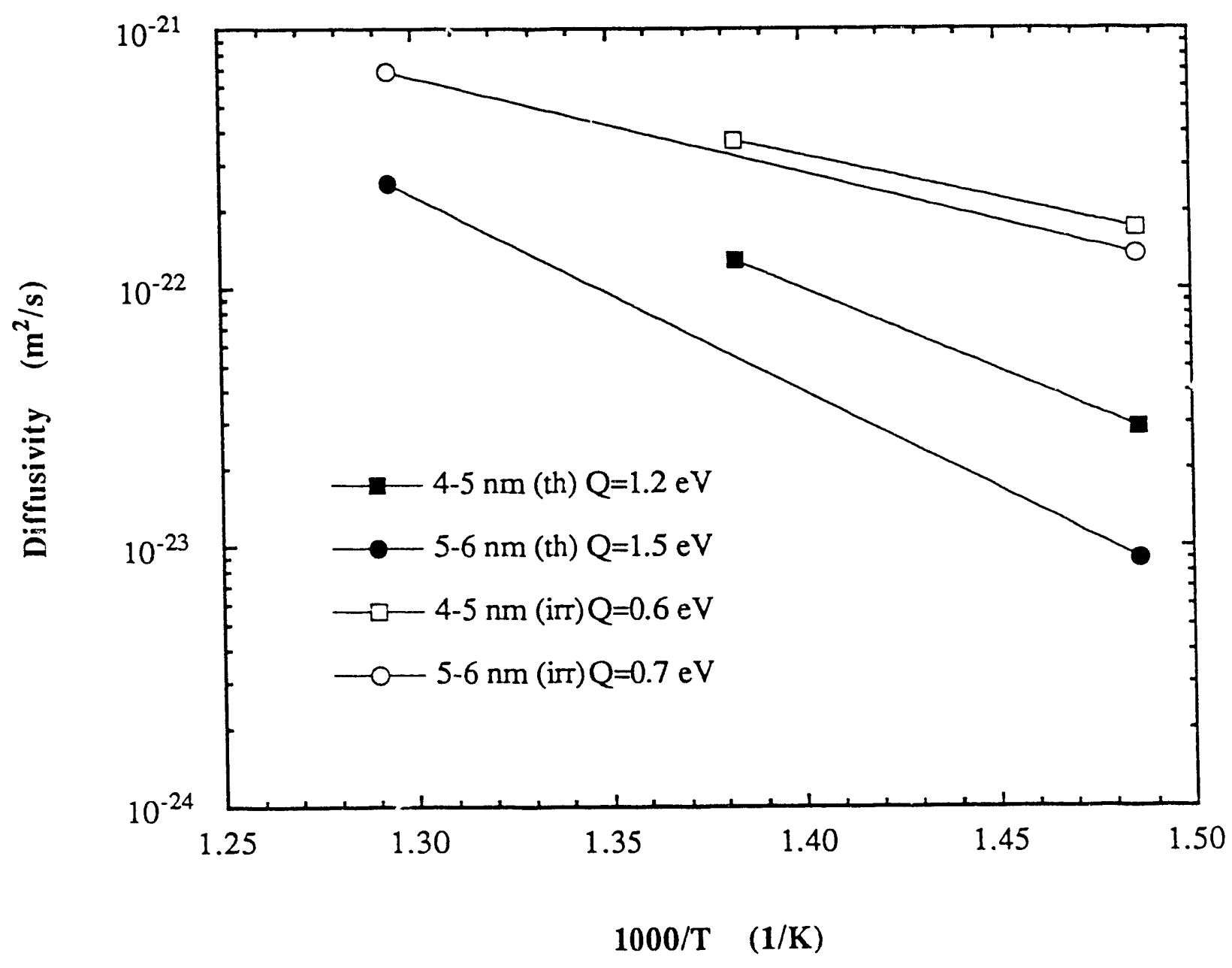



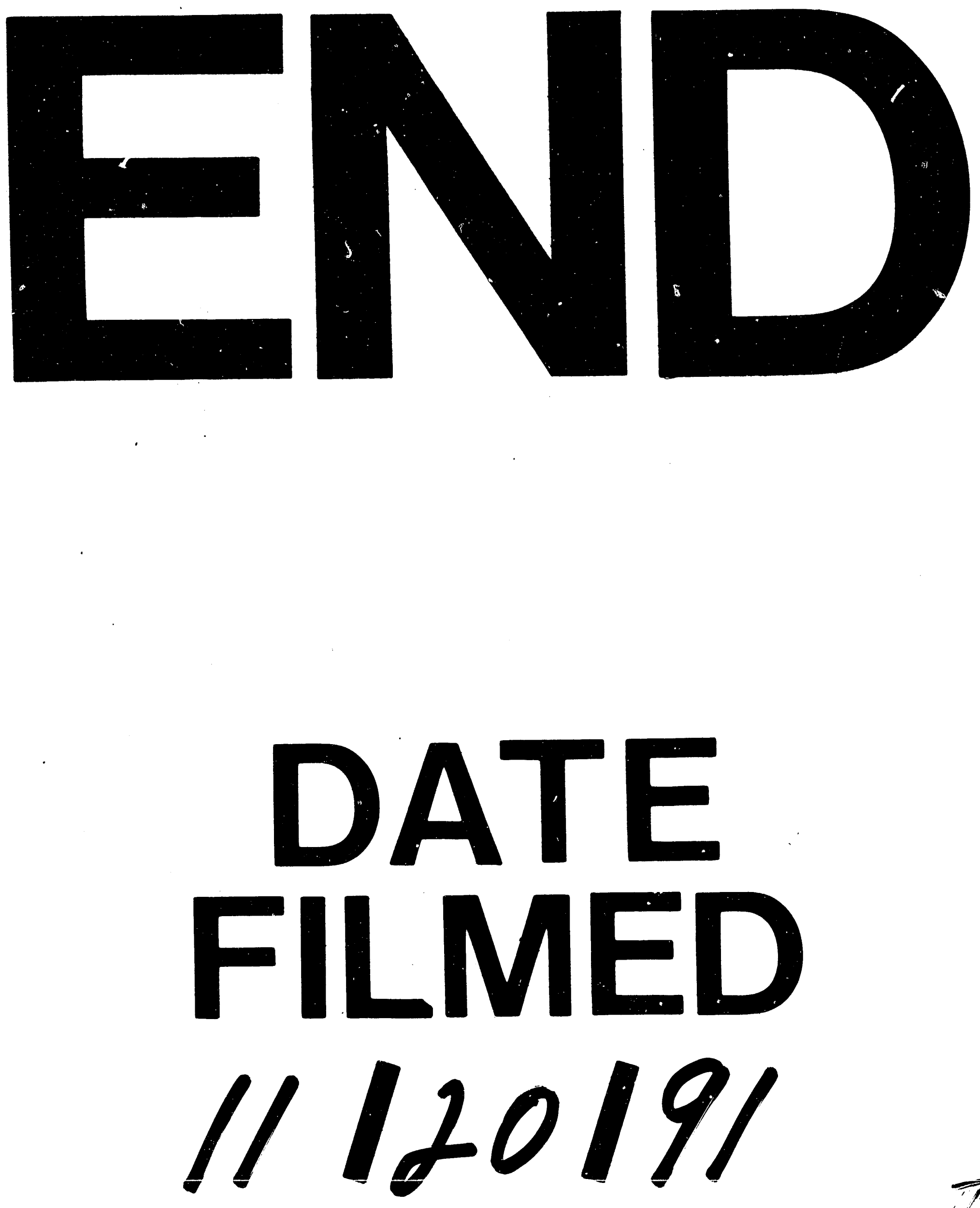

I 
